\title{
To Study Association between upper Gastrointestinal Symptoms and Body Mass Index in First Trimester of Pregnancy
}

\author{
${ }^{1}$ Ashish Gautam, ${ }^{2}$ Asha Nigam, ${ }^{3}$ Prabhat Agrawal, ${ }^{4}$ Ruchi Rani
}

\begin{abstract}
Aims: To study the association between upper gastrointestinal symptoms and body mass index (BMI) in the first trimester of pregnancy.

Objectives: To determine common upper gastrointestinal tract symptoms among women during their first trimester and to determine any association with the maternal BMI for their occurrence.
\end{abstract}

Materials and methods: Three hundred and forty-eight pregnant females during their first trimester who visited the outpatient department or causality were evaluated for their upper gastrointestinal symptoms. Their weight, height, and obstetric history were noted. Patients were evaluated for the presence of epigastric pain, nausea, vomiting, acid regurgitation, heart burn, early satiety, and loss of appetite after conception. Patients were grouped into three categories: Group A, with low BMI $\left(<20 \mathrm{~kg} / \mathrm{m}^{2}\right)$; group B, with average BMI $\left(20-22.9 \mathrm{~kg} / \mathrm{m}^{2}\right)$; and group $\mathrm{C}$, with high BMI $\left(>22.9 \mathrm{~kg} / \mathrm{m}^{2}\right)$. Symptoms were correlated with BMI.

Results: Patient were divided as follows: $26.6 \%(n=92)$ were in group $A, 53.6 \%(n=185)$ were in group $B$, and $20.5 \%(n=71)$ were in group C. In group A, $56(60.8 \%$ ) out of 92 developed new gastrointestinal symptoms and 51 out of 56 developed vomiting. In group B, 77 (41.6\%) out of 185 developed new gastrointestinal symptoms and 40 out of 77 developed vomiting. In group C, $45(63.3 \%)$ out of 71 developed new gastrointestinal symptoms and 29 out of 45 developed vomiting. Group A women are more prone to developing upper gastrointestinal symptoms than group B women, p-value being $0.003245(<0.05)$. Group C patients were more prone to developing upper gastrointestinal symptoms than group $B$ patients. There is no statistical difference between groups $A$ and $C$, p-value being 0.870 (>0.05).

Statistical analysis used: Chi-square test.

Conclusion: Both high and low BMI are associated with more risk of development of upper gastrointestinal symptoms.

\footnotetext{
${ }^{1,2}$ Assistant Professor, ${ }^{3}$ Associate Professor, ${ }^{4}$ Medical Officer

${ }^{1,3}$ Department of Medicine, SN Medical College, Agra, Uttar Pradesh, India

2Department of Obstetrics and Gynecology, SN Medical College Agra, Uttar Pradesh, India

${ }^{4}$ District Women Hospital, Agra, Uttar Pradesh, India

Corresponding Author: Ashish Gautam, Assistant Professor Department of Medicine, SN Medical College, Agra, Uttar Pradesh India, Phone: +919927089665, e-mail: dr_ashishgautam@ yahoo.co.in
}

Key message: Weight management prior to conception can reduce upper gastrointestinal symptoms during the first trimester.

Keywords: Body mass index, First trimester, Upper gastrointestinal symptoms.

How to cite this article: Gautam A, Nigam A, Agrawal P, Rani R. To Study Association between upper Gastrointestinal Symptoms and Body Mass Index in First Trimester of Pregnancy. J South Asian Feder Obst Gynae 2016;8(2):127-129.

Source of support: Nil

Conflict of interest: None

Date of received: 18 Dec 2015

Date of acceptance: 15 Feb 2016

Date of publication: April 2016

\section{INTRODUCTION}

There is no specific upper gastrointestinal disease that can be attributed to pregnancy. Hormonal changes, indeed, can cause significant symptoms associated with pregnancy. There may be worsening of previous problems like gastrointestinal reflux disease and inflammatory bowel disease, or there may be appearance of new nonspecific symptoms. Heart burn, nausea, and vomiting are extremely common during the first trimester, affecting almost 50 to $90 \%$ of the females. Physiological changes during the first trimester and anatomical changes during the second and third trimesters lead to most of these symptoms. Sometimes differentiation between benign and catastrophic symptoms can be very difficult and can end in devastating results. Only a keen observation and experience in managing gastrointestinal emergencies can help to clinch the early diagnosis of fatal conditions. Hyperemesis gravidarum is one such serious condition and its early recognition is lifesaving. First pregnancy, multiple pregnancies, and molar pregnancy are the common but unavoidable risk factors for hyperemesis gravidarum and other severe upper gastrointestinal manifestations. Modifiable risk factors that can lead to hyperemesis gravidarum are not yet defined. Ben-Aroya $Z$ et al published their work on vomiting in the first trimester of pregnancy and its association with the mother's body mass index (BMI). India is a developing country where a good number of mothers have a poor BMI. This gave the grounds to our study, and we proceeded with the aim to calculate the BMI of mothers in their first trimester and determine the upper gastrointestinal symptoms. 


\section{MATERIALS AND METHODS}

All females, in their first trimester of pregnancy and visiting the Gynecology and Obstetrics or the Medicine Outpatient Department or the causality of SN Medical College, Agra, for consultation, were evaluated for subject selection. Patients from the outdoor department of the District Women Hospital, Agra, were also evaluated for inclusion in the study. The duration of the study was 1 month, from January 1, 2016, to January 31, 2016. A total of 348 patients were selected after applying inclusion and exclusion criteria. Inclusion criteria include: (1) All female patients who are in their first trimester and need consultation pertaining to upper gastrointestinal tract; (2) patients taking any medications that can produce upper gastrointestinal symptoms like NSAIDS, any antibiotics, etc.; and (3) patients having any comorbid disease that can produce upper gastrointestinal symptoms like previous cholicystitis or gastric or duodenal diseases were excluded. Patients were asked for symptoms pertaining to the upper gastrointestinal tract: (1) Epigastric pain, (2) nausea, (3) vomiting, (4) acid regurgitation, (5) heart burn, (6) early satiety, and (7) loss of appetite after conception. Quantification of vomiting in terms of the number of episodes per day was taken. Gravida and parity status were noted. Height in centimeters and weight in kilograms were taken. Patients presented to causality first were stabilized for symptoms before being evaluated for the study.

\section{RESULTS}

The mean age of presentation is 25.19 years with standard deviation 3.08 and variance 9.53; the youngest female is 18 years and the oldest is 34 years. The number of females having gravida 1 are 90, 2 are 132, 3 are 98, 4 are 24, 5 are 5, and 6 are 1 . The average age of all patients is 25.05 years. Patients were grouped in three categories as per their BMI. Group A includes patients with low BMI, i.e., $<20 \mathrm{~kg} / \mathrm{m}^{2}$; group B includes normal BMI patients; i.e., between 20 and $22.9 \mathrm{~kg} / \mathrm{m}^{2}$; and group $\mathrm{C}$ includes patients with high BMI, i.e., $>22.9 \mathrm{~kg} / \mathrm{m}^{2}$. The number of patients in each group are $92(26.6 \%)$ in group A, $185(53.6 \%)$ in group B, and $71(20.5 \%)$ in group $C$. The average age of group $A$ is 24.71 years, group B is 25.52 years, and group C is 24.94 years. The average weight in group $\mathrm{A}$ is $44.13 \mathrm{~kg}$ $(39.8-52.0 \mathrm{~kg})$, in group B is $53.15 \mathrm{~kg}(42.3-66.3 \mathrm{~kg})$, and in group C is $57.30 \mathrm{~kg}(48.8-69.9 \mathrm{~kg})$. The average height of all females is $1.53 \mathrm{~m}$. The average BMI is 21.94 with standard deviation 1.65 and variance 2.74 . The average BMI in group A is $19.68 \mathrm{~kg} / \mathrm{m}^{2}\left(19.11-19.96 \mathrm{~kg} / \mathrm{m}^{2}\right)$, group B is $25.52 \mathrm{~kg} / \mathrm{m}^{2}\left(20.17-22.94 \mathrm{~kg} / \mathrm{m}^{2}\right)$, and group $C$ is $24.12 \mathrm{~kg} / \mathrm{m}^{2}\left(23.01-27.61 \mathrm{~kg} / \mathrm{m}^{2}\right)$ (Table 1$)$.

In group A, $56(60.8 \%)$ out of 92 developed new gastrointestinal symptoms and 51 out of 56 developed vomiting and 12 out of 56 had severe vomiting requiring hospitalization. In group B, $77(41.6 \%)$ out of 185 developed new gastrointestinal symptoms and 40 out of 77 developed vomiting and 5 out of 40 had severe vomiting requiring hospitalization. In group C, 45 (63.3\%) out of 71 developed new gastrointestinal symptoms and 29 out of 45 developed vomiting and 10 out of 29 had severe vomiting requiring hospitalization. Group A women are more prone to developing upper gastrointestinal symptoms than group B women, p-value being 0.003245 $(<0.05)$. Group C patients were more prone to developing upper gastrointestinal symptoms than group B patients. There is no statistical difference between groups $\mathrm{A}$ and C, $p$-value being 0.870 ( $p>0.05$ ). Of the 348 patients, 27 required hospitalization for significant symptoms but only 5 were diagnosed as having hyperemesis gravidarum. Out of the 5 patients hospitalized, 3 were from group A, 1 from group B, and 1 from group C.

\section{DISCUSSION}

Seventy to eighty percent of females develop significant upper gastrointestinal symptoms during their first trimester of pregnancy. ${ }^{1}$ Incidence is more in Western and developed countries than in the developing countries. ${ }^{2}$ This variation could be due to better and easily accessible health care in developed countries. Despite lower incidence of upper gastrointestinal symptoms, the incidence of hyperemesis gravidarum is high in developing countries. ${ }^{3}$ Incidence varies from 3 to 20 per 1,000 pregnancies. We diagnosed 5 out of 348 patients in our study. Complaints of upper gastrointestinal symptoms are more common in younger women, primigravidas, and women with less than 12 years of education, nonsmokers, and obese women. ${ }^{4}$ Besides these, there are many more reported risk factors and BMI is one of them. Maternal BMI is not very strongly proposed as a risk factor for the symptoms but a study by Depue et al observed that the risk of vomiting and hyperemesis gravidarum increased by $50 \%$ with obesity, ${ }^{5}$ which clearly points the importance of maternal BMI. However, in a study by Cedergren et al, low BMI $\left(<20 \mathrm{~kg} / \mathrm{m}^{2}\right)$ was associated with a $40 \%$ higher risk of hyperemesis gravidarum. ${ }^{6}$ Also there was decreased risk of hospitalization due to hyperemesis gravidarum with increasing obesity. A study of 33,647 women in Norway found that both low and high BMI are associated with severe upper gastrointestinal symptoms and hyperemesis gravidarum, but data is primarily targeted among nonsmoking females. ${ }^{7}$ It is postulated that underweight women with low BMI have low pre-pregnant estrogen levels and thus may have an exaggerated response during the first trimester when estrogen levels surge. ${ }^{8}$ In contrast, in obese women, fat deposits may neutralize placental 
Table 1: Properties of patients in different BMI groups

\begin{tabular}{|c|c|c|c|c|c|}
\hline Sl. no. & Properties & & Group A & Group B & Group C \\
\hline 1 & BMI & & $<20 \mathrm{~kg} / \mathrm{m}^{2}$ & $20-22.9 \mathrm{~kg} / \mathrm{m}^{2}$ & $\geq 23 \mathrm{~kg} / \mathrm{m}^{2}$ \\
\hline 2 & $\mathrm{~N}$ & & 92 & 185 & 71 \\
\hline 3 & Average age & & 24.71 years & 25.52 years & 24.94 years \\
\hline 4 & Average weight & & $44.13 \mathrm{~kg}$ & $53.15 \mathrm{~kg}$ & $57.30 \mathrm{~kg}$ \\
\hline 5 & Average height & & $1.5 \mathrm{~m}, \mathrm{SD} 0.05$ & $1.5 \mathrm{~m}, \mathrm{SD} 0.06$ & $1.5 \mathrm{~m}, \mathrm{SD} 0.08$ \\
\hline 6 & Average BMI & & $19.68 \mathrm{~kg} / \mathrm{m}^{2}$ & $22.2 \mathrm{~kg} / \mathrm{m}^{2}$ & $24.12 \mathrm{~kg} / \mathrm{m}^{2}$ \\
\hline \multirow[t]{6}{*}{7} & Gravida, $n=1$ & & 26 & 48 & 16 \\
\hline & & 2 & 33 & 72 & 27 \\
\hline & & 3 & 25 & 49 & 24 \\
\hline & & 4 & 8 & 15 & 1 \\
\hline & & 5 & 0 & 3 & 2 \\
\hline & & 6 & 0 & 0 & 1 \\
\hline 8 & Gl symptoms, $n$ & & $56(60 \%)$ & $77(41.61 \%)$ & $45(63.3 \%)$ \\
\hline a & Epigastric pain & & 32 & 22 & 34 \\
\hline b & Nausea & & 49 & 36 & 30 \\
\hline c & Acid regurgitation & & 10 & 8 & 35 \\
\hline$d$ & Heart burn & & 22 & 20 & 26 \\
\hline e & Early satiety & & 50 & 63 & 21 \\
\hline$f$ & Loss of appetite & & 53 & 71 & 14 \\
\hline g & Vomiting & & 51 & 40 & 29 \\
\hline $\mathrm{h}$ & Severe vomiting & & 12 & 5 & 10 \\
\hline
\end{tabular}

factors thought to contribute to the pathogenesis of gastrointestinal symptoms. ${ }^{6}$ Results from our study are similar to those from the study by Depue et al and the study from Norway. A significantly higher incidences of gastrointestinal symptoms are found in both patients with lower and higher BMI group as compared to patients with normal BMI. In a study by Ben-Aroya Z et al, a significantly higher number of patients with severe nausea and vomiting belong to either low or high BMI as compared to patients with normal BMI. ${ }^{9}$

\section{CONCLUSION}

Besides several other nonmodifiable risk factors for significant upper gastrointestinal symptoms, BMI is also an important risk factor. Targeting maternal weight before conception can check the gastrointestinal symptoms of first trimester and can also prevent the incidence of fatal conditions like hyperemesis gravidarum.

\section{ACKNOWLEDGMENTS}

Authors would like to thank all contributors from the PG Department of Medicine and the Department of Gynecology and Obstetrics, SN Medical College, Agra, for providing patients for this research project. I sincerely thank Dr. Asha for convincing patients to participate in the study. I also extend sincere thanks to Dr. Ruchi Rani, medical officer, District Women Hospital, Agra, for providing patients after counselling and Dr. Prabhat Agrawal for data compilation and statistical calculation.

\section{REFERENCES}

1. O'Brien B, Zhou Q. Variables related to nausea and vomiting during pregnancy. Birth 1995 Jun;22(2):93-100.

2. Semmens JP. Female sexuality and life situations: An etiologic psycho-socio-sexual profile of weight gain and nausea and vomiting of pregnancy. Obstet Gynecol 1971 Oct;38(4): 555-563.

3. Verberg MFG, Gillott DJ, Al-Fardan N, Grudzinskas JG. Hyperemesis gravidarm, a literature review. Hum Reprod Update 2005;11:527-539.

4. Klebanoff MA, Koslowe PA, Kaslow R, Rhoads GG. Epidemiology of vomiting in early pregnancy. Obstet Gynecol 1985;66:612-616.

5. Depue RH, Bernstsein L, Ross RK, Judd HL, Henderson BE. Hyperemesis gravidarum in relation to estradiol levels, pregnancy outcome and other maternal factors: Seroepidemiologic study. Am J Obstet Gynecol 1987 May;156(5):1137-1141.

6. Cedergren M, Brynhildsen J, Josefesson A, Sydsjö A, Sydsjö G. Hyperemesis gravidarum that requires hospitalization and the use of antiemetic drugs in relation to maternal body composition. Am J Obstet Gynecol 2008 Apr;198(4):412. e1-412.e5.

7. Vikanes A, Grjibovski AM, VangenS, Gunnes N, Samuelsen SO, Magnus P. Maternal body composition, smoking, and hyperemesis gravidarum. Ann Epidemol 2010 Aug;20(8): 592-598.

8. Rochelson B, Vohra N, Darvishzadeh J, Pagano M. Low prepregnancy ideal weight: height ratio in women with hyperemesis gravdiarum. J Reprod Med 2003 Jun;48(6): 422-424.

9. Ben-Aroya Z, Lurie S, Segal D, Hallak M, Glezerman M. Association of nausea and vomiting in pregnancy with lower body mass index. Eur J Obstet Gynecol Reprod Biol 2005 Feb 1;118(2):196-198. 